\section{"As glebas bárbaras do Brasil Central": os sertões de Mato Grosso e Goiás nas narrativas de viagem de Hermano Ribeiro da Silva, 1935-1936}

\section{"The barbarous glebes} of Central Brazil": the hinterlands of Mato Grosso and Goiás in the travel narratives of Hermano Ribeiro da Silva, 1935-1936

\section{Luciana Murari ${ }^{i}$}

'Professora, Escola de Humanidades/Pontifícia Universidade Católica do Rio Grande do Sul; Programa de Pós-graduação em História/Pontifícia Universidade Católica do Rio Grande do Sul. Porto Alegre - RS - Brasil

orcid.org/0000-0003-1517-1016

luciana.murari@pucrs.br

Recebido em 21 jun. 2019.

Aprovado em 4 out. 2019.
MURARI, Luciana. “As glebas bárbaras do Brasil Central": os sertões de Mato Grosso e Goiás nas narrativas de viagem de Hermano Ribeiro da Silva, 1935-1936. História, Ciências, Saúde - Manguinhos, Rio de Janeiro, v.27, n.4, out.-dez. 2020, p.1055-1075.

Resumo

$\mathrm{O}$ artigo analisa as narrativas de viagem ao interior de Mato Grosso e Goiás publicadas em 1935 e 1936 pelo explorador paulista Hermano Ribeiro da Silva, que obtiveram considerável sucesso editorial e impacto no meio letrado brasileiro. Concentramo-nos em suas ideias sobre a relação entre o ambiente do Brasil Central e o homem sertanejo, sobre as potencialidades de exploração econômica da região e sobre o papel do Estado na condução de iniciativas capazes de promover sua incorporação efetiva à nacionalidade. Buscamos também compreender a fundamentação de seu discurso em conceitos e esquemas científicos genéricos dotados de poder retórico e argumentativo.

Palavras-chave: narrativas de viagem; Centro-Oeste; Era Vargas; Hermano Ribeiro da Silva (1902-1937); sertão.

Abstract

The article analyzes the travel narratives to the hinterlands of the states of Mato Grosso and Goiás published in 1935 and 1936 by the São Paulo-based explorer Hermano Ribeiro da Silva, which proved a great publishing success and had a considerable impact on lettered society in Brazil. The analysis focuses on his ideas about the relationship between the environment in Central Brazil and the man who inhabited it, the potential economic exploitation of the region, and the role of the State in orchestrating initiatives capable of promoting its effective incorporation into the nationhood. It also seeks to understand how he grounded his discourse on generic scientific concepts and schemas endowed with rhetorical and argumentative power.

Keywords: travel narratives; Central West; Vargas Era; Hermano Ribeiro da Silva (1902-1937); sertão. 
E m 1935, o jornalista Hermano Ribeiro da Silva publica pelas Edições Cultura Brasileira, de São Paulo, Nos sertões do Araguaia: narrativa da expedição às glebas bárbaras do Brasil Central. Nesse livro, o escritor registra os eventos e as impressões de uma viagem realizada por ele em 1932 ao noroeste de Goiás e, em seguida, em direção ao território localizado às margens do rio das Mortes, afluente do Araguaia. Com a recepção favorável dessa narrativa, no ano seguinte o autor publicou relatos e um diário de viagem cronologicamente anteriores em Garimpos de Mato Grosso: viagens ao sul do estado e ao lendário rio das Garças. Essas expedições, que conferiram ao autor o status de sertanista, faziam parte de uma onda de caravanas de origens diversas que, com os mais diferentes propósitos, acorriam ao Brasil Central naquele momento.

Este artigo analisa as concepções que presidem a representação do ambiente sertanejo nas narrativas do autor, partindo do estudo do substrato ideológico que fundamenta seu discurso, em busca de se impor como um narrador legítimo e de elevado propósito social. Para definir sua abordagem, adotamos como perspectiva a visão territorial do espaço, positivamente demarcado e considerado objeto do comando político estatal. Nesse aspecto, visamos à manifestação de posicionamentos intelectuais a respeito do exercício do poder jurídico-institucional sobre a base física da nacionalidade, englobando a defesa da soberania e o estudo dos seus potenciais de exploração econômica, conforme a autoridade estabelecida como direito de domínio pelo Estado nacional brasileiro. Em questão está ainda o problema da população, também objeto de sua autoridade e recurso produtivo necessário à apropriação objetiva do ambiente (Haesbaert, 2009, p.62-63). Nesse sentido, população e território definem conjuntamente a originalidade do espaço sertanejo e, como veremos, são objetos inter-relacionados na abordagem do autor.

A partir da compreensão dos fundamentos sociais e intelectuais do escritor, interrogamos suas obras como registro de uma práxis de produção de conhecimento e de exploração da natureza. Partimos, assim, do estudo da lógica interna que preside a assimilação e a veiculação de uma imagem do espaço físico do Brasil Central ${ }^{1}$ para a população letrada, promovendo uma leitura inquisitiva que busca não apenas a compreensão das obras, mas também os pontos que extravasam e perturbam o discurso instrumental e programático do autor. Para tanto, as fontes são estudadas como construções mentais em que o registro do vivido é moldado por valores político-ideológicos e por esquemas figurativos consagrados pelo imaginário e pela cultura histórico-científica de seu tempo. Com isso, acreditamos ser capazes de compreender suas categorias cognitivas de apreensão e interpretação do vivido, assim como as dinâmicas interativas que conferem à natureza sertaneja uma determinada inteligibilidade e sentido. Essas narrativas são compreendidas, portanto, como uma busca por aproximar o leitor de uma realidade outra em relação a seu mundo organizado e institucionalizado, oferecendo uma imagem e um significado àquela região até então opaca e ininteligível no restante do país, genericamente conhecida, na época, como os "sertões".

Atualmente esquecidos, os relatos de viagem do escritor encontraram excepcional repercussão em sua época, o que pode ser confirmado pela aquisição de exemplares para as bibliotecas de escolas secundárias, juntamente com livros didáticos, clássicos literários e obras regionalistas (Edital, 1935). Além disso, observa-se o generoso número 
de resenhas sobre eles na imprensa em todo o país. O volume de Garimpos de Mato Grosso encerra-se com uma coletânea de trechos de artigos favoráveis a Nos sertões do Araguaia, publicados em jornais do Rio de Janeiro, de São Paulo, do Ceará, de Pernambuco, do Paraná e de Minas Gerais (Silva, 1936, p.315-320). O primeiro livro de Hermano chegou a ser reproduzido em capítulos no pé de página do jornal República, de Florianópolis, o que também exemplifica sua considerável difusão e aceitação para além das divisas paulistas (Nos sertões..., 17 maio 1935).

Esse sucesso pode ser atribuído à sua convergência com temas de grande impacto na época: a difusão de ideologias nacionalistas que conduziam à exacerbação do interesse pelos mais variados temas brasileiros, a crença em virtuais ameaças à soberania nacional vinculadas à instabilidade do cenário internacional, a promoção do desenvolvimento econômico pelo regime varguista, a acentuada consciência da diversidade do território e da população brasileira, a curiosidade a respeito das regiões mais selvagens do país, a prosperidade potencial representada pelos recursos naturais distribuídos pelo território, a generalização da mentalidade estatista, que atribuía ao poder central a tarefa de conduzir os rumos do Brasil no sentido da redenção de seus males sociais. Esses temas, fortemente interligados, foram discutidos nos relatos de viagem de Hermano Ribeiro da Silva, louvados por seu valor patriótico, sua capacidade informativa e seu poder de despertar a atenção do leitor por meio da emoção proporcionada pelas narrativas de aventuras.

O autor desses livros está longe de poder ser considerado um intelectual no sentido estrito do termo, ou seja, não é alguém excepcionalmente dotado de conhecimentos técnico-científicos, acadêmicos ou culturais. Pelo contrário, não fazendo parte do que de mais aprofundado ou relevante então se produzia na forma de estudos sistemáticos e metodologicamente fundamentados, suas obras adquirem interesse justamente por veicular a interpretação própria da experiência por parte de um homem letrado, representativo de uma absorção mediana e genérica de saberes, redirecionando o olhar "dos picos rochosos para o fundo dos vales; das obras mais ou menos imortais para o saco de gatos", como definiu Michel Winock (1996, p.289). Neste artigo analisamos suas obras como instrumentos de difusão de uma dada representação do Brasil Central, explorando sua leitura da realidade sertaneja a partir do olhar testemunhal e da busca incessante pela significação do vivido.

\section{Sertanista e bandeirante}

Em conferência no Instituto Histórico e Geográfico de São Paulo realizada em 6 de novembro de 1960, Tito Lívio Ferreira mencionava o recentemente publicado Outras memórias, de Luís Tenório de Brito, em que o antigo ajudante de ordens de Washington Luís rememorava as "festas que marcavam época" patrocinadas pelo presidente de São Paulo para "animar a sociedade bandeirante", em meados dos anos 1920. Em um desses episódios festivos, o memorialista havia sido chamado a atender na portaria do salão ao "jovem e simpático Hermano Ribeiro da Silva (mais tarde famoso sertanista)" que, "apesar da casaca bem ajustada que envergava, ali se encontrava, barrada a entrada pela ausência do convite", ansiando por se juntar à noiva que já havia ingressado no baile. Luiz Tenório recordava décadas mais tarde o resultado feliz de sua intervenção: "momentos depois, 
via-se a silhueta elegante de Hermano Ribeiro da Silva volteando com a amada aos ritmos estonteantes da orquestra" (citado em Ferreira, 15 jan. 1961).

A referência a Hermano Ribeiro da Silva apela para o insólito ao associar o explorador dos sertões, celebrizado por suas narrativas de viagem ao centro geográfico do Brasil, aos eventos luxuosos da alta sociedade paulista em seu apogeu. Esses não eram, entretanto, nos anos 1920 e 1930, polos opostos no horizonte cultural e ideológico de São Paulo. Pelo contrário, tratava-se de um momento em que a "sociedade bandeirante" mostrava-se excepcionalmente dedicada à celebração de sua origem. Não é possível afirmar o quanto a conversão do filho de um dos velhos troncos paulistas ao sertanismo pode ter sido de fato motivada ou estimulada por esse culto dos antepassados. No entanto, o fundamento do discurso do explorador era o apelo a uma cultura histórica que pressupunha a liderança de uma elite tradicional, transferindo ao presente o decantado heroísmo do passado e preenchendo-o de propósitos nacionalistas.

O escritor explicita sua ascendência logo nas primeiras páginas de Nos sertões do Araguaia, em que se define como "paulista, descendente dos portugueses da descoberta e batizado com o sinete do sangue tupi" (Silva, 1935, p.17). No livro seguinte, atribuía a motivação de suas viagens a um certo "inconsciente atávico vindo das afastadas gerações dos bandeirantes" (Silva, 1936, p.21). O mito do bandeirantismo, que passou a ser cultivado em São Paulo a partir dos últimos anos do século XIX, ganhara forte impulso a partir da década de 1910, em busca de um passado nobilitador que permitisse à elite regional arrogar-se à condição de elite de sangue e fazer frente, assim, às ameaças à tradição identificadas com a ascensão de novas elites, particularmente os imigrantes (Ferreira, 2002; Sevcenko, 1992; Oliveira, 2006). A leitura do Brasil Central elaborada pelo escritor será feita a partir dessa identidade com o bandeirante, figura histórica à qual são atribuídos evidentemente anacrônicos dotes de idealismo e altruísmo. ${ }^{2}$ O contexto da década de 1930 é decerto de aguçamento do interesse pelos temas nacionais, o que pode ser comprovado pela vitalidade e o dinamismo da produção intelectual do país, onde, além do romance social que caracterizou a criação literária de então, multiplicavam-se publicações de "estudos brasileiros", em áreas como a antropologia, a linguística, a história e a geografia (Martins, s.d.). Todos esses elementos, e mais alguns, estão presentes nas narrativas de Ribeiro da Silva, amalgamados por uma dicção dividida entre a pretensa objetividade em direção ao mundo externo e o empenho ideológico capaz de legitimar suas viagens como feitos significativos em âmbito nacional, que poderiam conectar a experiência presente a uma missão patriótica dotada de fundamento histórico.

Além do retorno simbólico às origens bandeirantes, diferentes motivos são citados pelo escritor para explicar sua conversão ao sertanismo. Segundo ele, como naquele momento era generalizado no país o interesse pela situação nacional, cabia aos jornalistas e intelectuais realizar um esforço para atender a essa demanda, uma vez que "a bibliografia indígena carece, ao contrário, de ter a larga contribuição de trabalhos puramente objetivos, de caráter descritivo e ameno, a fim de que sejam acessíveis ao nosso grande público, cujas preferências ainda se não encantaram pelos estudos científicos integrais, que requerem grupos de cultura especializada apenas denunciados no país" (Silva, 1936, p.8-10). Como se vê, o escritor passava ao largo da realização de estudos científicos consistentes e da produção sistemática de conhecimento, atribuindo a "amenidade" de suas narrativas a um desígnio 
de popularização da informação sobre a realidade nacional. Como lembra Paula Montero (2012, p.110), “[a]s comissões de toda sorte que atravessaram a hinterlândia no período [republicano], tinham a função estratégica de dar a conhecer e sensibilizar as elites urbanas para a existência dessa nação clandestina, consolidar a vinculação e a defesa militar do território, e homogeneizar as diferenças entre a vida urbana e rural".

A analogia histórica das expedições de Ribeiro da Silva com o bandeirantismo atendia, portanto, às expectativas da cultura paulista de sua época e será não apenas repetida por ele como aceita generosamente pela recepção de seus livros dentro e fora de São Paulo. O escritor não encontrara no sertão um território "vazio" onde o homem branco se deparava com uma natureza "intocada" e com tribos "isoladas". Pelo contrário, em determinado ponto de sua viagem a Goiás ele chegou a definir ironicamente o interior do Brasil Central como uma "estupenda cidade cosmopolita", dada a afluência de visitantes de diversas partes do mundo à região, na condição de cientistas, exploradores, esportistas, jornalistas, missionários protestantes e católicos (em geral estrangeiros) e aventureiros em busca de ouro e diamante (Silva, 1935, p.253).

Vários fatores explicam a vulgarização do interesse pela região central do Brasil entre o público. Um deles era um evento midiático internacional, a busca por Percy Fawcett, coronel inglês que, obcecado por encontrar uma imaginária civilização antiga, havia desaparecido no Brasil Central em 1925, o que motivou a realização de várias expedições para investigar seu paradeiro, desde grupos oficiais até caçadores de recompensa e de notoriedade. ${ }^{3} \mathrm{O}$ primeiro apêndice de Nos sertões do Araguaia é dedicado a uma denúncia de "toda espécie de absurdas mistificações e mesmo de assaltos às bolsas incautas" causadas pelo fenômeno Fawcett, o que representaria um grande prejuízo para a ciência (Silva, 1935, p.297). Ribeiro da Silva já havia se manifestado sobre o tema em 1934, quando o aventureiro italiano Miguel Trucchi concedeu uma entrevista em que declarava ter encontrado o coronel inglês vivendo entre nativos, curado da lepra por remédios indígenas (O homem..., 17 out. 1934; A expedição..., 19 out. 1934). Um desses grupos de "exploradores" em busca de Fawcett, formado por esportistas e aventureiros ingleses, cruza o caminho do viajante paulista no vale do Araguaia, o que rendeu referências a ele, identificado como "Herman", no célebre livro Brazilian adventure, de Peter Fleming (1940, p.290-295), originalmente publicado em 1933.

Chegavam ainda ao sertão cientistas e investidores, na expectativa de explorar oportunidades econômicas, como era o caso das iniciativas privadas de transporte e navegação que ali atuavam. Outro atrativo foi a abertura de núcleos mineradores no sul de Mato Grosso e na região do rio das Garças, garimpos onde os próprios membros da expedição do escritor somaram-se a estrangeiros e brasileiros de diversas regiões em busca da fortuna, além de empreender esforços para localizar novas jazidas. O rio das Garças havia se tornado de fato lendário no imaginário nacional. Dá testemunho disso o livro infantil O garimpeiro do rio das Garças, lançado em 1924 por Monteiro Lobato. A ficção descreve a trajetória heroica de um protagonista que luta contra a natureza do sertão e a violência de criminosos e, ao final, é recompensado pela riqueza e pela nobilitação: "voltou para a cidade, construiu o palácio, casou-se e morreu conde - o senhor conde do Rio das Garças" (Lobato, 2012, p.62). 
Acreditamos, aliás, que a busca da riqueza tenha sido a motivação (inconfessada) das primeiras viagens de Hermano, que a partir daí assumiu a postura de sertanista, passando a se dedicar a objetivos de exploração e produção de conhecimento sobre o Oeste ${ }^{4}$ brasileiro. Os apelos da cultura de massa e o velho fascínio exercido por narrativas de viagem junto ao público leitor convergiam, assim, na obra do aventureiro paulista e de outros exploradores e aventureiros que acorriam à região. ${ }^{5}$ Como escreve um dos resenhistas de Nos sertões do Araguaia,

[d]iversos descobridores têm narrado travessias dramáticas. Inúmeros sertanistas já relacionaram os lances principais das aventuras nas selvas. Muitos heróis já nos deram conta dos seus programas, de aventuras intrépidas. Mas há ainda o que dizer... Desde o general Couto de Magalhães que os curiosos avançam pelo Araguaia, para de lá trazer notícias espantosas. As tribos indígenas, as feras, a floresta misteriosa, tudo ali estimula a fantasia. Entre os livros nacionais os que narram lendas, descrevem aspectos e fixam perspectivas dos lugares selvagens da nossa terra são os que nos despertam maior interesse (Pontes, 12 ago. 1935).

Vê-se, portanto, que o componente documental das narrativas de viagem ao centro do país não dissolvia a mística do território selvagem como parte das expectativas dos leitores, alimentadas pelo próprio viajante quando resume seu livro como um relato de "peripécias" vividas por "despreocupados aventureiros", enfarados da vida civilizada, seduzidos pela literatura sobre o sertão e em busca de sensações fortes (Silva, 1936, p.108). Entretanto, apesar dessa modéstia retórica que identifica os viajantes com o desejo do grande público pela aventura em terras exóticas, seus propósitos eram elevados, uma vez que definidos como parte de uma missão patriótica dedicada não apenas à revelação do Brasil ao público leitor médio, mas também a uma simbólica conquista territorial, similar àquela realizada pelos bandeirantes mitológicos ao ampliar virtualmente os limites da América portuguesa. "[N]o recôndito da alma dos habitantes de todos os estados, existe latente a esplêndida chama tutelar de brasilidade que empolgou os nossos antepassados", ideia que demonstra tanto a generalidade do interesse pelas grandes questões nacionais entre o público quanto a busca de uma legitimidade histórica capaz de fundamentar o simbólico "retorno" do grupo paulista às terras sertanejas (Silva, 1936, p.8).

$\mathrm{Na}$ convergência entre a busca de aventura, a tentativa da sorte nos garimpos e a motivação exploratória, um dos objetivos declarados por Ribeiro da Silva para empreender suas viagens era "conhecer alguma coisa do interior do país, ou pouco mais além do nada que se conhece", trabalhando para comunicar ao público leitor a existência de um Brasil "olvidado", "ignorado", "abandonado" por uma nacionalidade aferrada ao litoral e voltada para fora, negligente e ignorante dos problemas nacionais, segundo um repertório vocabular consagrado pela expressão patriótica sobre assuntos sertanejos (Silva, 1936, p.8). O argumento é claramente inspirado em Euclides da Cunha - não por acaso autor da epígrafe de Nos sertões do Araguaia -, ideólogo maior dessas incursões em território "bárbaro" em nome de uma arremetida nacional "civilizadora". A viagem de Hermano ao sertão do Brasil Central guarda em comum com Euclides a retórica das demandas e/ ou denúncias às consciências nacionalistas e ao Estado em favor do cumprimento de sua 
"dívida" para com os territórios e as populações interioranas, processo que também pode ser lido como uma convocação para sua conquista pelos portadores da dita "civilização". ${ }^{6}$ O discurso sobre o sertão brasileiro fazia uso constante, também, do tema da ameaça à soberania, dada a ausência de signos evidentes de vigilância e controle territorial que pudessem oferecer resistência a possíveis ataques externos. De fato, a movimentação de grupos adventícios dentro do país havia já despertado a atenção do sistema jurídico-político nacional, que buscou exercer controle sobre as expedições exploratórias de qualquer natureza, nacionais ou estrangeiras, que se organizassem para percorrer o interior. Em 1933 havia sido promulgado o decreto n.22.698, que criava o Conselho de Fiscalização das Expedições Artísticas e Científicas, vinculado à Diretoria Geral de Pesquisas Científicas do Ministério da Agricultura. ${ }^{7}$ Estabelecia-se a responsabilidade do ministério pela fiscalização das expedições brasileiras de iniciativa particular e de todas as expedições estrangeiras pelo território nacional, submetendo-as à sua autorização. Os grupos vindos do exterior tinham sua aprovação condicionada à incorporação de participantes brasileiros indicados pelo governo, que custearia sua participação se a iniciativa fosse considerada de interesse nacional. Estabeleciam-se, ainda, restrições ao transporte de espécimes de qualquer natureza para o exterior e regras para a partilha do material recolhido, considerando a disponibilidade desses exemplares nos institutos científicos e no Museu Nacional (Estados..., 11 maio 1933).

Nessas circunstâncias, a crítica do viajante à inércia do Estado poderia parecer infundada, dado esse esforço de regulamentação. No entanto, em sua avaliação, ainda que bemintencionada e movida pela defesa dos interesses nacionais, a vigilância das expedições era inócua na proteção dos sertões brasileiros, uma vez que, mesmo que observados os dispositivos legais, eles não seriam capazes de evitar "possíveis ideias de expansionismos econômicos ou territoriais de nações estranhas" (Silva, 1935, p.26). A iniciativa era, em sua opinião, obsoleta, pois uma região improdutiva e escassamente povoada como aquela não poderia ser "enclausurada", devendo ser convertida em objeto de estudos e propaganda para seu povoamento por brasileiros e estrangeiros. O escritor se autoatribuía uma missão que pode ser definida como de "territorialização do espaço", chamando a atenção para uma necessária apropriação do sertão pelo Estado, na forma de programas e projetos específicos para a região. Busca-se, assim, converter o "espaço" sertanejo em "território" brasileiro, uma vez que este último seria o produto de uma ação programática de apropriação objetiva ou representacional do primeiro (Raffestin, 1993).

Esse pensamento alia-se a um discurso defensivo, haja vista as "formidáveis tenazes dos imperialismos das guerras econômicas de conquista", contexto em que o isolamento do sertão participava de "toda uma incalculável série de fatores para aumentar o retardamento da soberania nacional, do ponto de vista da sua plena e palpável emancipação" (Silva, 1936, p.8). Dentro do esforço civilizador associado ao desbravamento do Brasil Central, nada mais eloquente da situação do país que a "enormidade" enunciada por um velho cuiabano e registrada por Hermano Ribeiro da Silva como uma demonstração dos contrassensos da vida sertaneja dentro do país: "Mas diz que a lei nova (a revolução) vai obrigar toda gente a entrar para a nação do Brasil" (Silva, 1936, p.118-119). O que o escritor define, espantado, como uma amostra da ignorância generalizada entre os sertanejos é um índice da ausência dos nexos esperados entre povo e Estado. 
Não podemos desconsiderar, por outro lado, que o espírito das narrativas do explorador se mantém fiel ao pressuposto de sua condição de paulista e herdeiro dos bandeirantes. Como narrador, o viajante se atribui papel similar ao da "vanguarda capitalista" identificada por Mary-Louise Pratt (1999) nos viajantes europeus que chegavam à América a partir da década de 1820: em questão está a busca de riquezas potenciais e matérias-primas, sendo os territórios desconhecidos repositórios a conquistar, desde que superados os obstáculos ao avanço civilizador. Curiosamente, o escritor busca no passado bandeirante orientação para a descoberta de tesouros que, a despeito de seu posicionamento como agente da racionalidade, comprovam seu apelo a um inegável componente mítico, deixando-se levar por relatos lendários para os quais busca fundamentos na documentação histórica, como aqueles sobre as lavras de Araés e Martírios,

as duas lavras do precioso metal que nos velhos tempos apaixonaram a cobiça dos mineradores paulistas. ... Martírios conforme depoimentos dos desbravadores das monções, deve enclausurar maravilhosa fortuna, e afora a sua constatação pelas bandeiras de Manoel de Campos e Bartholomeu Bueno, faz mais de dois séculos, nenhum outro cristão lá conseguiu aportar, quer devido aos ataques dos selvagens, quer devido às contradições dos itinerários existentes nos arquivos. Há cinco anos investigo a provável situação do tesouro, procurando localizá-lo através de todos os documentos de que me posso valer. E concluo agora alguma coisa de útil, descobrindo orientações que reputo persuasivas a respeito da celebrada mina (Silva, 1935, p.95).

Essa visão argentária da riqueza natural a ser retirada da terra chama a atenção para o lugar a ser ocupado por aquelas regiões centrais no espaço brasileiro. No caso das narrativas em questão, aos estados do centro geográfico do país era atribuído um lugar subsidiário na economia nacional, dada a inerente superioridade econômica do estado natal do autor, pois “[a]s terras do sertão não alcançam o índice habitual de fertilidade que conhecemos em São Paulo. Somos nisso a unidade mais favorecida pela natureza, que nos doou a mais larga extensão de matas do país, regadas perenemente por infinidade de cursos de água, a par do clima saudável e apropriado a inúmeras culturas" (Silva, 1936, p.24). O lugar daquele estado no contexto brasileiro equivale, nos livros do explorador, ao da Europa em relação aos domínios imperiais, como uma natureza temperada, desprovida de manifestações extremas, caracterizada pelo equilíbrio, pela amenidade, pela constância e a previsibilidade dos ciclos. Enquanto as terras paulistas estariam destinadas a produzir riquezas, modificando o ambiente natural por meio da agricultura, o Brasil Central, região de natureza "inferior", dramática e imprevisível, deveria dedicar-se a uma atividade de status também inferior, o extrativismo. De fato, a literatura de viagens assumiu, na era do colonialismo, a representação de formas peculiares de natureza:

Os aventureiros e exploradores do Iluminismo e do pós-Iluminismo podiam não mais temer as regiões remotas e os monstros de muitas cabeças, mas seus diários científicos e narrativas de viagens transmitiam para um público encantado uma vívida consciência dos excessos de outras naturezas - selvagens, luxuriosas e complexas; duras, vazias e estéreis - e a partir daí produziram essas outras naturezas 'como' outro. Através das partes emergentes e das divisões do espaço global a natureza europeia foi construída como natureza 'normal', enquanto outras naturezas, não temperadas, 
foram diagnosticadas como anormais, patológicas e mesmo naturezas 'não naturais' (Gregory, 2001, p.89; destaques no original). ${ }^{8}$

Naturezas "não naturais" como a do Brasil Central, não tão afortunadas quanto São Paulo, são vistas assim como bizarras e hostis, além de despossuídas dos recursos compatíveis com uma ascensão econômica derivada da criação de riquezas e do trabalho sistemático. Ainda que tivessem como alternativas a pecuária e a mineração, a exploração de óleos vegetais, fibras e frutas, isso dependeria de investimentos e de recursos vindos de fora, dada a habitual inércia do sertão. O reconhecimento do potencial econômico do Brasil Central dependia, assim, da inclusão de um componente racional e instrumental na abordagem da natureza, mas não dispensava a dramaticidade que dava o tom da representação da natureza como sujeito ativo na conformação da vida social, e que invade também os posicionamentos do autor a respeito da formação do sertanejo como tipo racial.

\section{O "drama que nos propomos representar"}

O contexto da "era imperialista de territorialização", como definido por Doreen Massey (2009), permite compreender a construção dos argumentos, diagnósticos e proposições do viajante. Trata-se de uma concepção tipicamente moderna responsável pelo pressuposto de que culturas, sociedades e nações guardam uma relação necessária com certos espaços delimitados, coesos e claramente diferenciados uns dos outros. Cada lugar demarcaria internamente uma identidade oposta a diferenças deslocadas para fora das fronteiras, o que sustentava uma imaginação geográfica que integrava um projeto global de organização do espaço em que os Estados-nações se consagravam como a própria expressão do progresso e adquiriam aspecto "natural". Daí a dificuldade epistemológica em traduzir o espaço sertanejo observada nas expressões constantes de estranhamento das narrativas de Hermano, também porque a sobreposição de identidades e percursos ao longo da viagem compromete a associação costumeira entre a diferença espacial e a sequência temporal em que se definia o progresso como lógica ecumênica.

No entanto, naquele contexto, as circunstâncias políticas internacionais e os próprios rumos do avanço capitalista enviavam ao sertão personagens desiludidos com as sociedades do hemisfério Norte e que buscavam alguma forma de redenção na América do Sul, por meio da procura da prosperidade nos garimpos, no engajamento em atividades econômicas ou do simples exílio. Apesar da amargura acumulada por esses personagens extraviados das sociedades industriais, o poder redentor da tecnologia e da ação estatal rege, inquestionado, a narrativa do explorador paulista, como instrumento por excelência para a necessária e urgente integração do sertão ao espaço brasileiro e, em última instância, à civilização ocidental.

Assim, os livros de Hermano Ribeiro da Silva aqui analisados participam de um processo de apropriação via representação, que faz com que o espaço em que ele se move tenha reforçada sua condição de parte integrante do território brasileiro, apesar da aparência de cosmopolitismo, abandono e desordem atribuída ao sertão. Segundo ele, seu papel era o de despertar nas novas gerações o interesse "pelos mistérios desse deserto territorial, em que 
permanecemos na inércia de perdulários inconscientes" (Silva, 1936, p.8-9). Essa retórica salvacionista legitima seus esforços como ações em prol da causa nacional, levadas a efeito por meio da observação da natureza e das populações locais, tanto os sertanejos quanto os indígenas, ambos definidos por sua interação recíproca e com o ambiente. Esses grupos se tornam, assim, objetos de interesse etnográfico, abordados a partir de um questionamento de seu potencial de conversão aos propósitos da nacionalidade, ou seja, de incorporação à vida econômica e social do país na condição de trabalhadores sedentários.

Nas narrativas de viagens escritas por Silva, o sertanejo é observado em sua rotina, buscando-se analisar os aspectos peculiares de sua mentalidade, práticas, costumes e sociabilidade, como tipo mestiço representativo da história brasileira de dispersão do povoamento pelo interior. O elemento nativo, por sua vez, é tratado em continuidade com o problema da soberania nacional, já que os indígenas e o território compõem a mesma problemática no discurso do sertanista. A mera existência de tribos isoladas era vista como uma falha do Estado nacional em seu dever de incorporação de "todos" os seus cidadãos, dentro da fórmula que associa em seu contexto a população, o território e a autoridade (Raffestin, 1993, p.23). Nesse ponto, encaixa-se perfeitamente à narrativa de Hermano Ribeiro uma observação feita por David Day (2013, p.222) a partir do exemplo norteamericano: "Na maior parte dos casos, entretanto, mesmo quando as sociedades vencedoras tiveram sucesso em povoar as terras que conquistaram, a continuidade da existência de povos indígenas se torna uma lembrança desconfortável de que suas próprias ligações com a terra são necessariamente mais fracas que aquelas dos povos preexistentes". ${ }^{9}$ Incompleta a conquista territorial, também restava incompleta a "incorporação" do autóctone. Daí se compreende a reafirmação constante pelo escritor do objetivo de realizar contato com populações incontaminadas pelo homem branco, como um corolário da aquisição de poder sobre a totalidade do espaço nacional.

No entanto, no ambiente do cerrado ${ }^{10}$ e da floresta, a população era ainda bastante rarefeita. Nem sequer haviam sido mapeados os principais acidentes geográficos do terreno, cujo marco simbólico mais importante era a serra do Roncador, próxima das aldeias dos indígenas xavantes, até então infensos ao contato com o homem branco. Em função de seu isolamento, as terras em que viviam são vistas em Os sertões do Araguaia como uma fronteira simbólica da civilização, espécie de tesouro a ser conquistado pelos exploradores, desafiados também pela dificuldade de acesso à região, dotada da mesma ferocidade e força de resistência dos xavantes.

Decerto, a presença dos "ameaçadores" indígenas nas obras do escritor paulista impulsiona o componente aventuresco e temerário da viagem e é apresentada como sintoma perturbador dos hiatos da nacionalidade no interior de seu próprio território, em que tribos selvagens distribuíam-se inconscientes do país a que pertenciam e imunes a sua atuação: "numerosas tribos indígenas, no primitivismo dos rudes costumes, campeiam ainda nas glebas virgens, onde o homem civilizado não as foi alterar com a sabedoria ou a conquista" (Silva, 1935, p.223). Registrando o genocídio indígena, o escritor reconhece, entretanto, que a "conquista" fornecia resultados irrisórios e estava muito distante da "sabedoria". Na interpretação dele, a luta entre nativos e colonizadores estava ainda em curso em todo o sertão, onde se mantinham as hostilidades entre "invasores" e "invadidos", "que terminam 
com a vitória fatal das balas dos semicivilizados" (Silva, 1936, p.69). O viajante decerto não se vê como "invasor", embora sua própria viagem faça parte de uma luta, simbólica e efetiva, de conquista do sertão. ${ }^{11}$ Do alto de sua condição de representante da vanguarda histórica de avanço "europeu" sobre a natureza bruta, o explorador transfere para sua viagem ao Brasil Central a lógica que presidiu o colonialismo, cujo discurso construiu geografias imaginativas voltadas para definir a diferença essencial entre territórios e populações, convertidos a objetos de sua prática de representação da alteridade. Um dos princípios da imposição do domínio europeu foi a crença em sua capacidade de garantir a vitória do "humano" sobre o "natural", construção conceitual elaborada pelo imaginário moderno, no qual o distanciamento em relação à irracionalidade da natureza impôs-se como medida de avanço cultural. Tratava-se, portanto, de dominar e domesticar o ambiente - assim como a própria dimensão animal do humano - como forma de libertação dos constrangimentos e da opressão da natureza, elemento feminino, em duas versões: a europeia - maternal, nutriz, benéfica - e a extraeuropeia - sedutora, destrutiva, selvagem -, ambas a submeter ao poder masculino da força física e da racionalidade (Gregory, 2001, p.84-90).

Em tal contexto, a exploração dos "nossos intérminos e ricos patrimônios" direciona o olhar de Hermano Ribeiro da Silva para o diagnóstico das potencialidades produtivas do sertão, como forma de afiançar sua ocupação, garantindo, assim, o completo domínio sobre o território. Uma manifestação evidente dessa busca de afirmação da soberania nacional é o poder de (re)nomeação dos acidentes geográficos como baliza da autoridade sobre o território: cursos d'água eram indicados por algarismos (rio 23, córrego 24, por exemplo), que se sobrepõem aos nomes indígenas "em vários batismos à revelia", na definição do escritor; outros são indicados por pontos de interrogação nas representações cartográficas, elaboradas em resposta à inespecificidade do mapa que guiava os avanços da comitiva do escritor, no qual ele identifica as incoerências da representação em face da realidade.

A posição do explorador diante do conhecimento é, por outro lado, bastante dúbia. Ao longo de suas narrativas, Ribeiro da Silva demonstra possuir alguma leitura em sociologia e ciências naturais, ${ }^{12}$ e declara uma erudição capaz de justificar o penoso transporte de três caixas de livros em sua viagem ao Mato Grosso. Embora fosse fundamentalmente um publicista, o escritor era dado a veleidades científicas: prometeu publicar um livro sobre os crenaques e tomou a si a responsabilidade pela pesquisa etnográfica em sua segunda viagem à serra do Roncador, realizada em $1937 .{ }^{13}$ Sua dicção era modelada por uma visão de mundo darwinista social subjacente, que partia da imagem da luta contra a brutalidade da natureza e da pressão exercida por esta, imagem que se estende à organização da sociedade e à distribuição de seus recursos produtivos, incorporando o elemento humano como resultante e ocasionalmente como vítima dessa violência latente. Nesse ponto, sua obra pode ser lida em continuidade com o paradigma prevalecente na produção intelectual brasileira desde as últimas décadas do século XIX, quando a relação entre homem e natureza no Brasil passou a ser representada pelas perspectivas do conflito e da contradição insolúvel (Murari, 2009). Como demonstrou Sandro Dutra e Silva (2019), o discurso em torno do enfrentamento da natureza teve continuidade, nos anos posteriores, com o processo de expansão colonizadora lançado por Getúlio Vargas em 1938, conhecido como a "Marcha para Oeste". 
No entanto, as elaborações do narrador a respeito da formação social sertaneja, no tocante à relação entre a formação étnica da população e o ambiente físico regional, compõem um conjunto eclético em termos teóricos. Na base de suas formulações está um evolucionismo difuso, que permite ao escritor observar os nativos como elementos do passado da humanidade, "a reeditarem aqui um comboio de idades passadas", como ele escreve a respeito de um grupo de jovens javaés (Silva, 1936, p.68). Da mesma maneira, é difícil para ele conformar-se com a ideia de que os hábitos que observa nos nativos durante uma refeição coletiva um dia teriam sido também adotados pelos brancos: "Parece inadmissível que os avós de toda a humanidade culta também incorressem em tamanhas indecências" (Silva, 1935, p.278).

Lugares-comuns darwinistas compõem, assim, suas perorações a respeito da formação do homem sertanejo. Incorporado ao senso comum como um verniz científico aplicado à argumentação cotidiana, a doutrina possuía uma eficácia retórica que residia justamente em sua imprecisão, na familiaridade de seus slogans genéricos e no aspecto imperativo de sua mecânica de ação e reação, suficientes para veicular uma interpretação habitual do processo histórico. Como afirma Mike Hawkins (1997, p.32), o darwinismo social é uma visão de mundo, devendo ser enfatizado seu papel discursivo: "O darwinismo social não é, em si, uma teoria política ou social. Ele consiste sobretudo de uma série de suposições conectadas e de proposições sobre a natureza, o tempo e como a humanidade se situa entre eles". ${ }^{14}$ Isso não significa que as muitas indeterminações teóricas do modelo o tornem tão inespecífico que ele possa se aplicar a qualquer situação, uma vez que existe uma série de pressupostos centrais que o sustentam: o materialismo científico, a rejeição do poder explicativo de qualquer força sobrenatural, a defesa da capacidade de transformação das formas de vida e a ideia da evolução do homem a partir de outras espécies. A capacidade de adaptação do darwinismo social é ampla, e existem limites para sua utilização, mas esse modelo só pode ser compreendido a partir da própria prática discursiva (Hawkins, 1997, p.34-35).

Assim, apesar da negação do darwinismo pelos cientistas ligados à expansão da pesquisa e do ensino biológico no país (Garfield, 2013; Duarte, 2010), entre o público amplo, aí incluídos os "intelectuais" medianos de formação generalista, como o autor em questão, a lógica da guerra pela sobrevivência persiste, apoiada em uma representação dramática da natureza tropical como força ameaçadora, hostil e implacável. Como terreno fértil para a produção de analogias e metáforas, o darwinismo social deu suporte a usos amplos da ideia da luta das espécies. Generalizou-se, no meio intelectual brasileiro, a crença de que, em determinados contextos, o ser humano deveria enfrentar as forças hostis do meio para sobreviver, caso fosse apto para tanto; do contrário, seria eliminado pela competição com grupos mais bem aquinhoados em termos físicos e mentais. Esse mecanismo é empregado pelo escritor para explicar o genocídio indígena durante o período de exploração aurífera, em que "[d] esapareceram, sucumbiram pela lei fatal a que se vêm submetendo as raças atrasadas. Deles ficou somente a sugestão do nome: Goiás" (Silva, 1935, p.37). Embora essas ideias soem anacrônicas para a década de 1930, como observou Shawn Miller (2007, p.1112), "poucos daqueles poderosos da América Latina queriam manter a possibilidade de que fatores políticos ou culturais pudessem explicar o desenvolvimento relativamente lento da 
região. Era mais fácil acreditar em determinismo e fatalismo que lutar para mudar, com grande risco social, o que, de fato, poderia ser mudado. Como resultado, a popularidade do determinismo e suas credenciais acadêmicas eram ascendentes até década de 1940 ". ${ }^{15}$

O sertanejo, por sua vez, é definido como mestiço brasileiro por excelência em Nos sertões do Araguaia:

A natureza amoldou aqueles cruzamentos para a luta gigantesca contra a barbaria da terra. E somente eles, como aconteceu antigamente aos admiráveis bandeirantes, conseguem suportar as agruras da opressão do ambiente. Anônimos e estoicos vão desbravando a pouco e pouco as glebas virgens, enquanto o impaludismo, os vermes intestinais, o mal de Chagas, as disenterias assaltam-nos, ceifando existências, destruindo saúdes" (Silva, 1935, p.18).

Subjacente a esses postulados está uma ideia de luta pela sobrevivência não apenas entre as espécies, mas dessas em geral contra o ambiente físico hostil, em que atuavam as patologias crônicas, as variações climáticas, as tempestades, as feras e mesmo os perturbadores insetos. Entretanto, "[a] natureza encarrega-se de reparar, assim, os mesmos flagelos que semeia", postula o escritor, supondo a existência de um sistema automático de ajuste entre homem e meio, a chamada "eugenia da seleção natural", entendida como um processo de eliminação daqueles que se mostrassem incapazes de sobreviver à agressividade do ambiente. Esse processo teria um saldo positivo, porque apesar dos indivíduos que sucumbem, a "civilização" descreve um avanço crescente dentro de um território antagônico (Silva, 1935, p.18).

O autor incorpora a seu raciocínio, inspirado nesse momento pela noção darwinista de luta contra o ambiente, uma concepção neolamarckiana, de tradição francesa, caracterizada pela pressuposição de que os resultados da interação dos organismos com seu ambiente poderiam ser incorporados, transmitidos e herdados pela descendência, garantindo um domínio crescente do meio pelo esforço humano. Em suas palavras, "a terra, e principalmente a terra tropical da América, recebendo o homem adventício que vem trabalhá-la a fim de colher os frutos para a sua felicidade material, obriga-o em troca disso a participar de suas emoções estranhas. E assimila-o por essa força incoercível da natureza bruta, que é e será sem dúvida a parcela mais imponderável da formação da nossa raça" (Silva, 1936, p.30). Na visão dele, o próprio empreendimento dos bandeirantes teria sido tributário do poder de adaptação garantido aos mamelucos pela mescla das etnias portuguesa e indígena, uma vez que esta última etnia teria uma resistência física superior nos ambientes tropicais. Portanto, se fosse possível curar o sertanejo, "soberano dentro do habitat insólito e bárbaro", "teríamos neles uma raça intrépida de vencedores" (Silva, 1935, p.241). Observe-se que o discurso (pseudo)científico se acomoda, aqui, à imagem mitificadora de uma natureza grandiosa que gera "emoções estranhas" com sua "força incoercível" de resultado "imponderável". Os processos fisiológicos efetivos dessa intervenção do meio na formação da etnia sertaneja não são explicitados para além desse emprego dramático da linguagem.

Conclui-se que o componente ativo da formação da identidade nacional não seria primordialmente a raça, mas o meio, que presidiria a transformação dela. Reduzindo o impacto da seleção natural e negando a luta pela sobrevivência, no neolamarckismo a força 
evolutiva precípua era atribuída à capacidade de projeção da mudança fisiológica em resposta aos estímulos ambientais. Pressupunha-se que os organismos incorporavam caracteres adquiridos a seu patrimônio genético, podendo assim transmiti-los a seus descendentes. Peter J. Bowler (2003, p.137) esclarece:

Quando os organismos mudam seus hábitos e usam seu corpo de forma diferente, o feito do uso e do não uso seria óbvio - isso é como o levantador de peso adquire músculos mais fortes. Se o novo hábito for mantido por muitas gerações e se o feito for transmitido, ainda que levemente, dos pais para sua descendência, então a modificação seria construída ao longo do tempo e um dia produziria uma mudança permanente. Se o novo hábito for útil e adquirido por toda a população, então por definição a mudança seria adaptativa ou intencional, como no caso das girafas que estenderam seus pescoços para alcançar uma nova fonte de alimento nas árvores. A variação dentro das espécies era direcionada, e não aleatória, assim não haveria indivíduos inaptos a eliminar por meio da luta. ${ }^{16}$

Coerentemente com o neolamarckismo, nos livros em debate Hermano Ribeiro da Silva favorece a adaptação ao meio como mecanismo evolutivo, de modo que, quanto maiores as dificuldades oferecidas por ele, mais intenso transcorria o processo de modelagem exercido pela natureza. A seleção natural, não de todo ausente na teoria neolamarckiana, comparece em sua argumentação como um derivado da adaptabilidade:

Tanto no litoral como no sertão, cujas populações se plasmaram sociologicamente de diversos modos, a seleção natural vem constituindo gerações que sucessivamente se integram cada vez mais no substrato do nosso ambiente geográfico discordante. Mas, se o aforismo se estende à etnografia de todo o país, na imensa zona do interior o nível de adaptação acha-se grandemente adiantado pelo poder do barbarismo da terra, fator preponderante e incoercível na assimilação de qualquer ser (Silva, 1936, p.137).

A visão da sociedade sertaneja em sua interação com o ambiente é elaborada pelo explorador a partir dessa representação da natureza como um poder despótico, em contraste com o tíbio desenvolvimento social e humano que é sua consequência. Os raciocínios do autor são, nesse ponto, pouco coerentes. Por um lado, as narrativas constroem uma visão negativa da população por sua suposta apatia e indolência. Algumas das expressões utilizadas por Silva (1935, p.31, 54, 1936, p.200) para definir os mestiços demonstram isso: ainda no trem que o conduziria a Goiás, um grupo de segunda classe de um trem de passageiros é visto como um "museu antropológico ambulante"; uma família de caboclos é definida como "porcos" que se deitam pelo chão cuspido e "roncam por cima dos outros"; o chefe de uma pequena povoação é um "antropoide apenas esperto", enquanto um dos interlocutores do autor é um "homem recém-saído da caverna". Por outro lado, ao passo que manifesta tais noções, o explorador enuncia diversas sentenças contra o racismo, a maioria delas apresentada como objeções a posicionamentos adotados por estrangeiros. A afirmativa retórica do estado de avançada adaptação da população ao meio geográfico segue sendo fundamental para a argumentação do autor que, apesar do diagnóstico da debilidade dos homens do sertão, reafirma sua capacidade de fundar as bases da ocupação do território: "[o]s caboclos, conquanto desarvorados pelas doenças e misérias, são os únicos racionais que conseguem suportar então a tremenda opressão das forças da natureza. Como que 
galvanizados pela desgraça, lá vão eles realizando o lento ciclo de desbravamento" (Silva, 1935, p.29).

Reafirma-se, assim, que o homem sertanejo é o perfeito exemplo da aclimatação de um tipo mestiço em um ambiente inóspito, ainda que as doenças destruíssem sua força de intervenção e o tornassem inapto à ação produtiva. Exemplo disso é um trecho em que Silva afirma que, no contexto de intensa concorrência representado pelos garimpos, os sertanejos enfraquecidos não logravam estabelecer-se em face da concorrência representada pelos tipos sadios, sobretudo os mestiços brasileiros de outras regiões e os estrangeiros, “todos eles espécimes temerários e resistentes a quantos empecilhos surgirem" (Silva, 1936, p.137). Nesse caso, como defensor da imigração europeia e asiática como alternativa para o povoamento do interior do Brasil, ${ }_{17}^{17}$ Silva (1936, p.31) afirma que esses estrangeiros "estão a plasmar um novo tipo sertanejo, cujo vigor e cuja iniciativa constituem logicamente um índice altamente favorável para a nossa ascensão progressista". Contraditoriamente com a teorização evolucionista do escritor, o sertanejo, produto da natureza, não se mostraria capaz, assim, de sobreviver à competição em seu próprio meio.

Nesse sentido, Hermano Ribeiro da Silva postula que a fusão étnica garantiria certa homogeneidade da população, operando a incorporação do estrangeiro, favorecida pela submissão de todos os tipos às mesmas condições ambientais. A incorporação de colonos adventícios e sua miscigenação com os nativos, observada inicialmente nas colônias agrícolas de São Paulo, aponta para um horizonte redentor. Desenha-se uma radical diferenciação entre as sociedades sertanejas tradicionais e os novos agrupamentos formados a partir da exploração das jazidas minerais, por exemplo, que faziam dos garimpeiros "pessoas estranhas ao modelo estandartizado dos caboclos, que vegetam os seus dias no ritmo pacífico e monótono do pastoreio e da lavoura" (Silva, 1936, p.138-139). Esses já eram, define o escritor, os tipos mais instruídos, dotados de maior iniciativa e menos aferrados à rotina, o que explicaria a dinâmica dos garimpos como resultado de um tipo de seleção que não favorece o mestiço regional em sua generalidade. Trata-se, nesse caso, de um uso sobretudo retórico dos termos científicos, pois a ideia de seleção remete aí a fatores prévios à chegada desses homens às zonas mineradoras - e determinantes dela.

O escritor recorre, por outro lado, ao poder evocativo do paralelismo entre homem e natureza, ao afirmar em outro trecho que as alternâncias da música sertaneja entre melodias chorosas e desafios cheios de valentia "parecem simbolizar a mesma turbulenta transformação da natureza que os rodeia, no paradoxal das brandas calmarias e das agitações despertadas pela brutalidade das forças latentes" (Silva, 1936, p.160). O discurso científico incorporado em linhas gerais pelo viajante é modelado por interpretações livres de termos que apelam para esse mesmo sentido analógico. A dramaticidade dos termos escolhidos remete à imagem de uma natureza plenipotente, que opera a transformação do elemento humano, a ser também submetido a um virtual enrijecimento determinado pela mestiçagem com o estrangeiro.

Assim, ainda que descreva mecanismos da seleção e da adaptação que atuariam para o ajuste dos organismos vivos a seu ambiente, a ação da natureza sobre o homem do sertão não conduz efetivamente, na visão de Ribeiro da Silva, ao melhor resultado. Refletindo sobre o potencial produtivo da região, o escritor conclui que "o desdobramento e a utilidade social 
da produção sertaneja permanecem sob a exclusiva dependência dos nossos dirigentes, no que respeita à sua atuação progressista. Porque se ficarem entregues apenas ao destino dos habitantes locais, a tarefa irá resolver-se com as calendas longínquas" (Silva, 1936, p.25). Daí se conclui que a intervenção estatal seria a única possibilidade de superação do atraso da região, sendo seu povo destituído de qualquer possibilidade de progresso por meios próprios, mesmo considerando o ingresso de elementos dinamizadores externos a essa sociedade, como no ambiente dos garimpos, já que não havia indicação de uma futura acomodação desses elementos em povoamentos permanentes.

Não há, por parte de Hermano Ribeiro da Silva, qualquer percepção da incoerência entre o uso de fundamentos científicos que desenhavam mecanismos naturais de ajuste entre o homem e o meio - e que, portanto, sinalizariam uma postura política individualista e liberal - e a defesa da intervenção estatal. O escritor mostra-se partidário da adoção de iniciativas econômicas por um poder executivo forte e centralizado que atuasse como um motor da história e como agente de proteção do interesse nacional em relação a entes privados e regionais, no sentido da imposição de uma autoridade única sobre o universo convulso e isolado do sertão. De fato, a ideia da necessidade de manejo racional da natureza pelo poder público, por meio de estruturas de controle técnico e administrativo, para favorecer o processo civilizador não era nova tampouco estranha ao panorama científico, tendo sido defendida por autores como o sociólogo norte-americano Lester Ward, em seu Psychic factors of civilization, já em 1893 (Worster, 1994). Em suas narrativas, Hermano Ribeiro da Silva observa situações específicas em que se faria necessária a "absoluta interferência do Estado, pois somente ele imporá a necessária unidade de ação para desenvolvimento do plano civilizado", na realização de iniciativas para ocupação econômica da terra.

Uma delas seria a promoção de empreendimentos como a Fordlândia, ${ }^{18}$ comandado por Henry Ford no município de Aveiro, no Pará, em terras concedidas pelo governo estadual, com o objetivo de abastecer de látex suas fábricas de automóveis a partir do plantio de seringueiras. De acordo com a proposta de Hermano, cabia ao Estado adotar estratégia idêntica de organização e racionalização do esforço produtivo, como forma de promoção da prosperidade do país. Outra intervenção tida como necessária seria a limitação do poder arbitrário e violento dos chefes da Companhia Mate Laranjeira, que possuía amplas concessões de exploração da erva-mate no Mato Grosso, em continuidade com suas terras no Paraguai. ${ }^{19}$ Similarmente, caberia às forças estatais a repressão das manifestações da prepotência e do absolutismo dos chefes locais sobre a população sertaneja, coerentemente com o pressuposto da centralização do poder como garantia da submissão das forças concorrentes à ordem estatal (Silva, 1935, p.23-24, 1936, p.90-91, 190-191).

\section{Considerações finais}

Como agente de promoção do capital, da técnica e da institucionalidade, ao Estado nacional é atribuída a capacidade de romper a lógica de submissão à barbárie natural até então prevalecente no sertão brasileiro. Com um discurso abertamente político, em tom alarmista Hermano Ribeiro da Silva clama pela presença dele nas terras que percorre, o que converge com o projeto já em curso de centralização do poder e incremento da intervenção 
estatal sobre a sociedade, como demonstra o próprio decreto de fiscalização das expedições exploratórias citado pelo escritor. Ao fim e ao cabo, essas demandas de centralização política e de recrudescimento do exercício da autoridade estatal apontam claramente para os rumos do regime varguista. A oposição do escritor por ocasião da Revolução Constitucionalista de 1934, que o encontra "extraviado" no Brasil Central e incapacitado de participar da resistência paulista, coloca em questão o centro irradiador desse poder, não sua natureza. Os rumos que ele aponta são aqueles mesmos que vinham sendo adotados pelo regime varguista e fortalecidos com a decretação do Estado Novo em 1937.

O sertão era a dimensão mais dramática do problema nacional brasileiro, o que as narrativas de viagem do explorador paulista evidenciam em seus relatos de peripécias, ameaças e provações, em que a força e a tenacidade dos aventureiros encenam os óbices à conquista do interior incivilizado pelas forças da racionalidade. O ecletismo teórico e a dificuldade de conciliação entre a visão determinista e o otimismo modernizador dão a medida da dificuldade do escritor de posicionar esse espaço desconhecido na modernidade a ser construída pela mão demiúrgica do Estado forte. Não podemos negar o compromisso assumido pelo viajante em contribuir para a transformação da realidade nacional a partir da produção de conhecimento sobre ela, particularmente no sentido da abertura de rotas em direção às terras até então inacessíveis. No entanto, as narrativas do escritor mantêm impressões contraditórias e embaraçosas quando se propõem a discorrer sobre o povo sertanejo, apesar do reconhecimento de suas virtudes de honestidade e honradez, da sensibilidade do viajante para o patético e de sua condenação da violência contra os humildes. Ao final, nas narrativas de Hermano Ribeiro da Silva, o sertão parece ter simultaneamente alimentado, fortalecido, deformado e abatido o sertanejo, personagem espantosamente ausente do futuro imaginado por ele para o Brasil Central.

\section{AGRADECIMENTO}

O presente trabalho apresenta resultados de pesquisas financiadas por bolsa de produtividade em pesquisa do Conselho Nacional de Desenvolvimento Científico e Tecnológico (CNPq), do Ministério da Ciência, Tecnologia e Inovações.

\section{NOTAS}

${ }^{1}$ A expressão "Centro-Oeste" passou a ser utilizada oficialmente a partir de 1942 para se referir aos estados de Goiás e Mato Grosso, quando foi realizada uma nova divisão regional do Brasil pelo Instituto Brasileiro de Geografia e Estatística (IBGE). O IBGE foi fundado em 1938, resultado da fusão do Instituto Nacional de Estatística com o Conselho Brasileiro de Geografia (Contel, 2014).

${ }^{2}$ Nos anos seguintes ao lançamento dos livros de Hermano Ribeiro da Silva, foram publicadas obras que assimilaram a expansão da fronteira durante o período colonial ao projeto de colonização do Estado Novo, como a síntese clássica de Cassiano Ricardo, Marcha para Oeste: a influência da bandeira na formação social e política do Brasil (1940). Outros autores buscaram identificar analogias entre o processo de expansão territorial no Brasil e o avanço da frontier norte-americana, tematizada por Frederick Jackson Turner nos últimos anos do século XIX, ainda que esse autor nem sempre seja claramente referenciado. É o caso de Bandeirantes e pioneiros (1955), de Clodomir Vianna Moog, Monções (1945) e Caminhos e fronteiras (1957), de Sérgio Buarque de Holanda, Pioneiros e fazendeiros de São Paulo, de Pierre Monbeig (edição original em francês, Pionniers et planteurs de São Paulo,1952). Sobre o tema, ver Oliveira (2000) e Wegner (2000). Estudos recentes, escritos na perspectiva teórico-metodológica da história ambiental, têm revisitado essa historiografia hoje clássica, como é o caso de Evans e Silva (2017), Silva (2017) e Silva (2018). 
${ }^{3}$ Sobre o caso Fawcett, a referência mais completa é o livro de David Grann (2009).

${ }^{4}$ O termo "Oeste" é aqui utilizado como sinônimo de Brasil Central. Nas obras de Hermano Ribeiro da Silva, ele designa apenas orientação ou localização geográfica. Por outro lado, a conotação mítica e simbólica do Oeste tem sido apontada por estudos como os de Silva (2017) e Wegner (2000).

${ }^{5}$ Diversos outros relatos de viagem ao Brasil Central foram publicados entre a década de 1920 e o final do primeiro governo Vargas. Dentre eles, citamos: A mais linda viagem: um "raid" de vinte mil quilômetros pelo interior brasileiro (1927), de Luis C. Gurgel do Amaral; Horrores e mistérios dos sertões desconhecidos:fatos tenebrosos, vividos pelo autor, numa expedição em procura do explorador inglês Cel. Fawcett, nos sertões amazônicos de Mato Grosso (relato apócrifo, de 1934), de João de Minas; Feras do pantanal (1935), de Alberto Vinhaes; Pelo Brasil Central (1938), de Frederico Augusto Rondon; Roncador (1939) e Sertões bravios (1940), de Willy Aureli; Do Brasil ao Paraguai: impressões de viagem e de costumes (1940), de Mário Leite; Roteiro dos Tocantins (1943) e O rio dos Tocantins (1945), de Lysias Augusto Rodrigues; Expedição ao rio Ronuro (1945), de Vicente de Paulo Teixeira da Fonseca Vasconcelos; Encantos do Oeste: um pedaço do Brasil onde o homem se identifica com a natureza (1945), de Agenor Couto de Magalhães.

${ }^{6}$ Sobre a interpretação euclidiana do problema nacional brasileiro, ver Murari (2007).

${ }^{7}$ A respeito da atuação efetiva do conselho sobre as iniciativas de pesquisa etnográfica realizadas no período, ver Grupioni (1998).

${ }^{8}$ No original: "Enlightenment and post-Enlightenment adventurers and explorers may no longer have feared remote regions and many-headed monsters, but their scientific journals and travel writings conveyed to an enthralled public a vivid sense of the excesses of other natures - wild, luxuriant, and tangled; harsh, empty, and barren - and hence produced other natures as other. Through the emerging partitions and divisions of global space European nature was constructed as 'normal' nature, while other, nontemperate natures were diagnosed as abnormal, pathological, and even 'unnatural' natures". Nesta e nas demais citações de obras em inglês, a tradução é livre.

${ }^{9}$ No original: "In most cases, though, even when supplanting societies have succeeded in peopling the lands they have conquered, the continuing existence of indigenous people provides a discomforting reminder that their own links to the land are necessarily weaker than those of the pre-existent peoples".

${ }^{10}$ Hermano Ribeiro da Silva não desenvolve nenhuma especulação sobre a especificidade do cerrado, termo do qual se utiliza para referenciar os trechos de mata encontrados ao longo de seu percurso na região. Trabalhos recentes, inspirados na história ambiental, têm se dedicado extensamente ao estudo dessa realidade físico-social. Destacamos: Giustina (2013), Funes (2013), Silva et al. (2017).

${ }^{11}$ Sobre a problemática dos nativos na obra de Hermano, ver Rodrigues, Murari (no prelo).

${ }^{12}$ O viajante menciona: Durkheim; a Sociologia, de Letourneau; as Leçons de sociologie (1922), do sociólogo durkheimiano Célestin Bouglé; L'homme, cet inconnu, do fisiologista Alexis Carrell (citados em Silva, 1936, p.157; 1935, p.228, p.12-13). Silva (1936, p.71) demonstra, ainda, algum conhecimento da literatura especializada em biologia, de que dão exemplo a Monografia brasileira de peixes fluviais e Animais venenosos do Brasil.

${ }^{13}$ Essa expedição, batizada de "Bandeira Anhanguera", foi a maior e mais organizada das empreendidas pelo explorador. Não deixou relato escrito de sua autoria, pois Hermano faleceu pouco antes do final da expedição, acometido de malária, em novembro de 1937.

${ }^{14}$ No original: "Social Darwinism is not, in itself, a social or political theory. Rather it consists of a series of connected assumptions and propositions about nature, time and how humanity is situated within both".

${ }^{15}$ No original: "[f]ew of those in power in Latin America wanted to entertain the possibility that nondeterministic cultural, political, and economic factors might explain the region's relatively slow development. It was easier to believe in determinism and fatalism than it was to struggle to change, at great social risk, what, in fact, could be changed. As a result, determinism's popularity and academic credentials were ascendant right into de 1940s".

${ }^{16}$ No original: "When the organisms changed its habits and used its body in different ways, the effect of use and disuse would be obvious - this is how the weightlifter acquires stronger muscles. If the new habit were kept up over many generations, and if the effect were transmitted, however slightly, from parent to offspring, then the modification would build up over time and eventually produce a permanent change. If the new habit were a useful one taken up by the whole population, then by definition the change would be adaptative or purposeful, as in the case of the giraffes which stretched their necks to reach a new source of food in the trees. Variation within the species was directed, not random, so there were no unfit individuals to be eliminated by struggle". 
${ }^{17} \mathrm{O}$ debate em torno das políticas de promoção da imigração tornava-se particularmente complexo em uma conjuntura caracterizada pela permanência de crenças racialistas, incorporadas pelos princípios eugênicos e pelo nacionalismo defensivo em ascensão. Já na Constituição Federal de 1934, haviam sido estabelecidas cotas para ingresso de estrangeiros no país, o que, com a decretação do Estado Novo, conduz à promulgação de leis restritivas mais severas. Sobre o tema, ver Koifman (2015). Especificamente sobre o Brasil Central, Sandro Dutra e Silva (2017) registrou o privilégio concedido à imigração interna no povoamento da Colônia Agrícola de Goiás, a partir de 1941.

${ }^{18}$ O processo prolongou-se desde a concessão de terras, em 1927, ao encerramento da iniciativa, malsucedida, em 1945. Para uma história da Fordlândia, ver Grandin (2010).

${ }^{19}$ A respeito, ver Arruda (1997).

\section{REFERÊNCIAS}

A EXPEDIÇÃO...

A expedição Trucchi. Correio Paulistano, p.5. 19 out. 1934.

\section{ARRUDA, Gilmar.}

Frutos da terra: os trabalhadores da Matte Larangeira. Londrina: Editora UEL. 1997.

BOWLER, Peter J.

Evolution: the history of an idea. Berkeley: University of California Press. 2003.

CONTEL, Fabio Betioli.

As divisões regionais do IBGE no século XX (1942, 1970 e 1990). Terra Brasilis, n.3, p.1-20. Disponível em: <http://journals.openedition. org/terrabrasilis/990>. Acesso em: 26 out. 2018. 2014.

\section{DAY, David.}

Conquest: how societies overwhelm others. Oxford: Oxford University Press. 2013.

DUARTE, Regina Horta.

A biologia militante: o Museu Nacional, especialização científica, divulgação do conhecimento e práticas políticas no Brasil, 1926-1945. Belo Horizonte: Editora UFMG. 2010.

\section{EDITAL.}

Edital. 13 ${ }^{\mathrm{a}}$ distribuição geral de 1935 às bibliotecas de escolas secundárias etc. Jornal do Brasil, p.19. 7 nov. 1935.

\section{ESTADOS...}

Estados Unidos do Brasil. Decreto n. 22.698, de 11 de maio de 1933. Incumbe ao Ministério da Agricultura de fiscalizar as expedições nacionais, de iniciativa particular e as estrangeiras, de qualquer natureza, empreendidas em território nacional, solicitando o concurso de outros ministérios, sempre que se tornar necessário. Disponível em: <http://www2.camara.leg.br/ legin/fed/decret/1930-1939/decreto-22698-11maio-1933-505601-publicacaooriginal-79943-pe. html>. Acesso em: 6 jul. 2018. 11 maio 1933.
EVANS, Sterling; SILVA, Sandro Dutra e. Crossing the green line: frontier, environment and the role of 'bandeirantes' in the conquering of Brazilian territory. Fronteiras, v.6, n.1, p.120-142. Disponível em: <http://periodicos. unievangelica.edu.br/index.php/fronteiras/ article/view/2190>. Acesso em: 2 set. 2019. 2017.

FERREIRA, Antonio Celso.

A epopeia bandeirante: letrados, instituições, invenção histórica, 1870-1940. São Paulo: Editora Unesp. 2002.

FERREIRA, Tito Livio.

Do santo condestável ao condestável do cristianismo. O Estado de S. Paulo, p.104. 15 jan. 1961.

FLEMING, Peter.

Brazilian adventure. London: World Books. 1940.

FUNES, Eurípedes.

Sertão cerrado. In: Silva, Sandro Dutra e.

Fronteira Cerrado: sociedade e natureza no Oeste do Brasil. Goiânia: Editora da PUC Goiás. p.125142. 2013.

GARFIELD, Seth.

In search of the Amazon: Brazil, the United States, and the nature of a region. Durham: Duke University Press. 2013.

GIUSTINA, Carlos Christian Della.

Degradação e conservação do Cerrado: uma história ambiental do estado de Goiás. Tese (Doutorado) - Centro de Desenvolvimento Sustentável, Universidade de Brasília, Brasília. Disponível em: <http://repositorio. unb.br/bitstream/10482/14387/1/2013 CarlosChristianDellaGiustina.pdf $>$. Acesso em: 13 set. 2019. 2013.

GRANDIN, Greg.

Fordlândia: ascensão e queda da cidade esquecida de Henry Ford na selva. Rio de Janeiro: Rocco. 2010 . 
GRANN, David.

$Z$, a cidade perdida: a obsessão mortal do coronel Fawcett em busca do Eldorado brasileiro. São Paulo: Companhia das Letras. 2009.

GREGORY, Derek.

(Post)colonialism and the production of nature. In: Castree, Noel; Braun, Bruce. Social nature: theory, practice, and politics. London: Blackwell. p.84-111. 2001.

GRUPIONI, Luís Donisete Benzi. Coleções e expedições vigiadas: os etnólogos no Conselho de Fiscalização das Expedições Artísticas e Científicas no Brasil. São Paulo: Hucitec; Anpocs. 1998.

HAESBAERT, Rogério.

O mito da desterritorialização: do 'fim dos territórios' à multiterritorialidade. Rio de Janeiro: Bertrand Brasil. 2009.

\section{HAWKINS, Mike.}

Social darwinism in European and American thought, 1860-1945: nature as model and nature as threat. Cambridge: Cambridge University Press. 1997.

KOIFMAN, Fábio.

Imigrante ideal: o Ministério da Justiça e a entrada de estrangeiros no Brasil, 1941-1945. Rio de Janeiro: Civilização Brasileira. 2015.

LOBATO, Monteiro.

O garimpeiro do rio das Garças. São Paulo: Globo. 2012.

MARTINS, Wilson.

História da inteligência brasileira. v.6. São Paulo:

T.A. Queiroz. s.d.

MASSEY, Doreen.

Pelo espaço: uma nova política da espacialidade. Tradução Hilda Pareto Maciel e Rogério Haesbaert. Rio de Janeiro: Bertrand Brasil. 2009.

MILLER, Shawn William.

An environmental history of Latin America.

Cambridge: Cambridge University Press. 2007.

MONTERO, Paula.

Selvagens, civilizados, autênticos: a produção das diferenças nas etnografias salesianas, 1920-1970. São Paulo: Edusp. 2012.

MURARI, Luciana.

Natureza e cultura no Brasil, 1870-1922. São Paulo: Alameda; Fapesp. 2009.

MURARI, Luciana.

Brasil, ficção geográfica: ciência e nacionalidade no país d'Os sertões. Belo Horizonte: Fapemig; São Paulo: Annablume. 2007.
NOS SERTÕES...

Nos sertões do Araguaia. República, p.1. 17 maio 1935.

O HOMEM...

O homem que viu Fawcett. Correio Paulistano, p.1. 17 out. 1934 .

OLIVEIRA, Lucia Lippi.

Os italianos, os bandeirantes e os modernistas paulistas. In: Oliveira, Lucia Lippi. Nós e eles:

relações culturais entre brasileiros e imigrantes. Rio de Janeiro: Editora FGV. p.43-81. 2006.

OLIVEIRA, Lucia Lippi.

Americanos: representações da identidade nacional no Brasil e nos EUA. Belo Horizonte: Editora UFMG. 2000.

PONTES, Eloy.

No mundo das letras. O Globo, p.5. 12 ago. 1935.

PRATT, Mary Louise.

Os olhos do Império: relatos de viagem e transculturação. Tradução Jézio Hernani Bonfim Gutierre. Bauru: Edusc. 1999.

RAFFESTIN, Claude.

Por uma geografia do poder. Tradução Maria Cecília França. São Paulo: Ática. 1993.

RODRIGUES, Cintia Régia; MURARI, Luciana. "Os nossos bugres": as expedições de Hermano Ribeiro da Silva ao Brasil Central e a questão indígena. Revista de História Regional, no prelo.

SEVCENKO, Nicolau.

Orfeu extático na metrópole: São Paulo sociedade e cultura nos frementes anos 20. São Paulo: Companhia das Letras. 1992.

SILVA, Hermano Ribeiro da.

Garimpos de Mato Grosso: viagens ao sul do estado e ao lendário rio das Garças. São Paulo: J. Fagundes. 1936.

SILVA, Hermano Ribeiro da.

Nos sertões do Araguaia: narrativa da expedição às glebas bárbaras do Brasil Central. São Paulo: Cultura Brasileira. 1935.

SILVA, Sandro Dutra e.

Nature's revenge: war on the wilderness during the opening of Brazil's 'Last Western Frontier'. International Review of Environmental History, v.5, n.1, p.5-21. Disponível em: <http://press-files. anu.edu.au/downloads/press/n5284/pdf/01_ dutra.pdf $>$. Acesso em: 14 set. 2019. 2019. 
SILVA, Sandro Dutra e.

"Heroes" of the sertão: the bandeirantes as a symbolic category for the study of Brazilian West colonization. Territórios e Fronteiras, v.11, n.1, p.60-76. Disponível em: <http://ppghis. com/territorios\&fronteiras/index.php/v03n02/ article/view/793 >. Acesso em: 15 mar. 2019. 2018.

SILVA, Sandro Dutra e.

No Oeste, a terra e o céu: a expansão da fronteira agrícola no Brasil Central. Rio de Janeiro: Mauad X. 2017.

SILVA, Sandro Dutra e et al.

O cerrado goiano na literatura de Bernardo Élis sob o olhar da história ambiental.

História, Ciências, Saúde-Manguinhos, v.24, n.1, p.93-110. Disponível em: <http://www. scielo.br/pdf/hcsm/v24n1/0104-5970hcsm-S0104-59702016005000024.pdf>. Acesso em: 12 maio 2018. 2017.

WEGNER, Robert.

A conquista do Oeste: a fronteira na obra de Sérgio Buarque de Holanda. Belo Horizonte: Editora da UFMG. 2000.

WINOCK, Michel.

As ideias políticas. In: Remond, René. Por uma história política. Rio de Janeiro: Editora FGV. p.271-294. 1996.

WORSTER, David.

Nature's economy: a history of ecological ideas. Cambridge: University of Cambridge. 1994. 